\title{
Resveratrol and quercetin-induced apoptosis of human 232B4 chronic lymphocytic leukemia cells by activation of caspase-3 and cell cycle arrest
}

\author{
Aysun Adan Gokbulut ${ }^{1}$, Elif Apohan ${ }^{1,2}$, Yusuf Baran ${ }^{1}$ \\ ${ }^{1}$ Department of Molecular Biology and Genetics, İzmir Institute of Technology, Urla, İzmir, Turkey, \\ ${ }^{2}$ Department of Biology, İönü University, Malatya, Turkey
}

\begin{abstract}
Chronic lymphocytic leukemia (CLL), defined by accumulation of pathogenic B cells, has a very complex biology due to various factors such as inherited, host, and enviromental factors. Recently, finding new therapeutic agents or development of novel treatment strategies have been paid attention. Resveratrol and quercetin, important phytoalexins found in many plants, have been reported to have cytotoxic effects on various types of cancer. In this study, we examined cytotoxic, cytostatic, and apoptotic effects of these two important phenolic compounds on 232B4 human CLL cells. Cytotoxic effects of resveratrol and quercetin were determined by MTT cell proliferation assay. Changes in caspase-3 enzyme activity were measured using caspase-3 colorimetric assay. Annexin V-FITC/PI double staining was performed to measure apoptotic cell population. Effects of resveratrol and quercetin on cell cycle profiles of CLL cells were investigated by flow cytometry. Treatment of CLL cells with resveratrol and quercetin caused dose dependent inhibition of cell proliferation and increased apoptotic cell population through induction of caspase-3 activity. Cell cycle analysis displayed cell cycle arrest mainly in G0/G1 for both polyphenols. Our data, in total, showed for the first time that resveratrol and quercetin might block CLL growth through inducing apoptosis and cell cycle arrest.
\end{abstract}

Keywrods: Chronic lymphocytic leukemia, Resveratrol, Quercetin, Apoptosis

\section{Introduction}

Chronic lymphocytic leukemia (CLL), the most common type of leukemia in the Western world, affects mainly adults. ${ }^{1}$ CLL cells are originated from antigen-stimulated mature B lymphocytes that either avoid death by external signals or die by apoptosis. Therefore, CLL is characterized by the clonal proliferation and accumulation of antigen experienced B lymphocytes in the blood, bone marrow, lymph nodes, and spleen. ${ }^{2,3}$ Several genetic aberrations have been identified in CLL. The most common one is a deletion at $13 q 14.3$ (IGHV). The other mutations include 11q22-23 (ATM), 17p13 (p53), and 6q21 deletions. ${ }^{4}$ These abnormalities are responsible for the formation of CLL and some of its clinical outcomes.

Although there are many therapeutic regimens, CLL is still an incurable disease. ${ }^{1}$ Current treatment possibilities include conventional chemotherapy,

Correspondence to: Yusuf Baran, İzmir Institute of Technology, Science Faculty, Department of Molecular Biology and Genetics, Urla, 35430 İzmir, Turkey. Email: yusufbaran@iyte.edu.tr, iytecancer@gmail.com monoclonal antibodies and hematopoietic transplantation. ${ }^{5}$ However, these standart treatment methods are not sufficient to remove all CLL cells and have their own side effects. Therefore, developing new strategies or agents that could eliminate CLL cells, resistant to apoptosis, is urgently required. Recently, there is an increasing interest in the usage of agents derived from natural products for cancer therapy. Plant products with strong antioxidant activities are called polyphenols and their effects on cell proliferation, gene regulation and apoptosis have been studied on several cancer cells. ${ }^{6}$

Resveratrol (trans-3,4',5-trihydroxystilbene), a kind of naturally occurring polyphenolic compound, is produced in a wide variety of plants like the skin of red grapes, peanuts, and mulberries to protect them against pathogenic attacts, injury and UV radiation., 7,8 It is very well known that resveratrol shows antioxidant, cardioprotective, chemopreventive, anticarcinogenic, antiproliferative and anti-inflammatory effects both in vivo and in vitro. ${ }^{9,10}$ Resveratrol has been 
shown to induce apoptosis in a variety of cancers such as chronic myeloid leukemia (CML), acute myeloid leukemia (AML), breast, prostate, colon and lung cancers. $^{11-13}$ The exact mechanism of resveratrol mediated anticancer effect is not fully identified. As indicated in several studies, resveratrol-induced apoptotic mechanisms include inhibition of retinoblastoma $(\mathrm{Rb})$ phosphorylation, suppression of $\mathrm{NF}$ $\kappa \mathrm{B}$ and STAT3, induction of $\mathrm{p} 21^{11,14}$ and ceramide synthases and inhibition of sphingosine kinase-1 and glucosyle ceramide synthase. ${ }^{12,13}$ It has been also shown that resveratrol inhibits the cell cycle progression by causing arrest at G1/G2 phases. ${ }^{15}$

Quercetin, an abundant polyphenol of the flavonoid family, is generated in onions, apples, red grapes, and other fruits and vegetables. ${ }^{16}$ The study of quercetin as a potential anticancerogen has been paid attention due to its high toxicity on cancer cells compared with its relatively scarce effects on normal cells. The anticancerogenic effects of quercetin on numerous cancer cells including melanoma cells, colon, breast, endometrial, T-cell acute lymphoblastic leukemia (ALL), acute promyelocytic leukemia, and chronic myeloid leukemia (CML) cells has been described. ${ }^{17}$ Mechanisms of quercetin triggered apoptosis include activation of caspases, upregulation of Bax and Bak and downregulation of $\mathrm{Bcl}-2$ and $\mathrm{Bcl}-\mathrm{xL}$ and inhibition of telomerase enzyme activity. ${ }^{18-20}$ Morever, quercetin inhibits PI3 K-Akt/PKB pathway responsible for cell survival and proliferation. In some cancer cell types, quercetin induces apoptosis by upregulating death receptor-5. ${ }^{21}$

In this study, we have shown that resveratrol and quercetin, most abundant polyphenols, have cytotoxic and apoptotic effects on human 232B4 CLL cells. These two polyphenols induce apoptosis through loss of mitochondrial membrane potential and increases in caspase-3 enzyme activity.

\section{Materials \& methods \\ Chemicals}

Resveratrol was obtained from Sigma-Aldrich (MO, USA). Resveratrol was dissolved in dimethylsulfoxide (DMSO) at a final concentration of $10 \mathrm{mM}$, stored at $-20^{\circ} \mathrm{C}$. Quercetin was obtained from Prof. Dr. Güray Saydam from Ege University, Department of Hematology. $10 \mathrm{mM}$ stock solution of quercetin was prepared in DMSO and stored at $-20^{\circ} \mathrm{C}$. The final concentration of DMSO did not exceed more than $0.1 \%$ in culture.

\section{Cell lines and culture conditions}

Human 232B4 CLL cells were kindly provided by Prof. Dr. Ander Rosen from Linköping University. The cells were grown and maintained in RPMI-1640 medium containing $10 \%$ fetal bovine serum and $1 \%$ penicillin-streptomycin at $37^{\circ} \mathrm{C}$ in $5 \% \mathrm{CO}_{2}$.

\section{Measurement of cell growth by MTT cell proliferation assay}

The IC50 values (drug concentration that inhibits cell proliferation by $50 \%$ ) of resveratrol and quercetin were determined from cell proliferation plots obtained by MTT assay. Briefly, $2 \times 10^{4}$ cells were seeded into 96-well plates containing $100 \mu \mathrm{L}$ growth medium in the absence or presence of increasing concentrations of resveratrol and quercetin. After 24-, 48- and 72 hours incubation periods for resveratrol and 72 hours for quercetin, the cells were treated with $20 \mu \mathrm{L}$ of MTT reagent for 4 hours. Then, the plates were read under $570-\mathrm{nm}$ wavelengths by ELISA reader (Thermo Electron Corporation Multiskan Spectrum, Vantaa, Finland). Finally, IC50 values of resveratrol and quercetin were calculated from the cell proliferation plots. $^{22}$

\section{Measurements of caspase-3 enzyme activity}

Changes in caspase-3 enzyme activity of the cells treated with increasing concentrations of resveratrol and quercetin for 48 hours were examined by caspase-3 colorimetric assay kit (BioVision Research Products, CA, USA). In short, the cells $\left(1 \times 10^{6}\right.$ cells $/ 2 \mathrm{~mL} /$ well) were collected by centrifugation at $1000 \mathrm{rpm}$ for 10 minutes. $50 \mu \mathrm{l}$ of chilled cell lysis buffer was added onto pellets. The obtained cell lysates were incubated on ice for 10 minutes and centrifuged at $10000 \mathrm{~g}$ for 1 minutes. Supernatants were transferred to new Eppendorf tubes and the reaction mixture containing $50 \mu \mathrm{l}$ of $2 \mathrm{X}$ reaction buffer (containing $10 \mathrm{mM}$ DTT), $50 \mu \mathrm{l}$ of sample and $5 \mu \mathrm{l}$ of DEVD-pNA substrate was prepared in 96 well plate and incubated for 2 hours at $37^{\circ} \mathrm{C}$ in a $\mathrm{CO}_{2}$ incubator. Then, the plate was read under $405 \mathrm{~nm}$ wavelengths by ELISA reader (Thermo Electron Corporation Multiskan Spectrum, Vantaa, Finland). The absorbance values are normalized to protein concentrations determined by Bradford assay.

\section{Evaluation of apoptosis}

For detection of apoptosis, Annexin V-FITC apoptosis detection kit (BioVision Research Products, CA, USA) was used with minor modifications and percentage apoptosis was measured by flow cytometry analysis. 232B4 cells $\left(1 \times 10^{6} / 2 \mathrm{~mL} /\right.$ well $)$ were exposed to different concentrations of resveratrol and quercetin for 48 hours. After treatment, cells were collected, washed twice with PBS, and resuspended in $500 \mu \mathrm{L}$ binding buffer. Later, $5 \mu \mathrm{L}$ of annexin V-FITC and $5 \mu \mathrm{L}$ of propidium iodide (PI) were added to the suspension and the cells were then incubated in the dark for 15 minutes at room temperature. Samples were then analyzed by flow cytometer. This method is 
based on the detection of phosphatidylserine (PS) which is translocated from the inner face of the plasma membrane to the cell surface soon after the induction of apoptosis. PS can be easily detected by staining with a fluorescent conjugate of Annexin V.

\section{Cell cycle analysis}

The effects of different concentrations of resveratrol and quercetin on cell cycle profiles of 232B4 cells at 48 hours were detected in the presence of DNase-free RNase and propidium iodine (PI) by flow cytometry. For cell cycle analysis, $232 \mathrm{~B} 4$ cells $\left(1 \times 10^{6} / 2 \mathrm{~mL} /\right.$ well) were collected by centrifugation at $1200 \mathrm{rpm}$ for 5 minutes and supernatants were removed. Then, pellets was dissolved with $1 \mathrm{ml}$ of cold PBS. After resuspension of pellets, $4 \mathrm{ml}$ of cold absolute ethanol was added to the pellets with gentle vortexing. The cell suspension was kept at $-20^{\circ} \mathrm{C}$ at least for 1 day. At the day of staining, the samples were centrifugated at $1200 \mathrm{rpm}$ for 10 minutes at $4^{\circ} \mathrm{C}$. Supernatants were removed and pellets were resuspended in $5 \mathrm{ml}$ cold PBS. Samples were centrifugated at $1200 \mathrm{rpm}$ for 10 minutes. Then, pellets were dissolved in $1 \mathrm{ml}$ of PBS-triton (100X). $100 \mu \mathrm{l}$ RNAase-A $(200 \mu \mathrm{g} / \mathrm{ml})$ was added onto the solution and incubated at $37^{\circ} \mathrm{C}$ for 30 minutes. Finally, the cells were stained with $100 \mu \mathrm{l}$ PI $(1 \mathrm{mg} / \mathrm{ml})$ and incubated at room
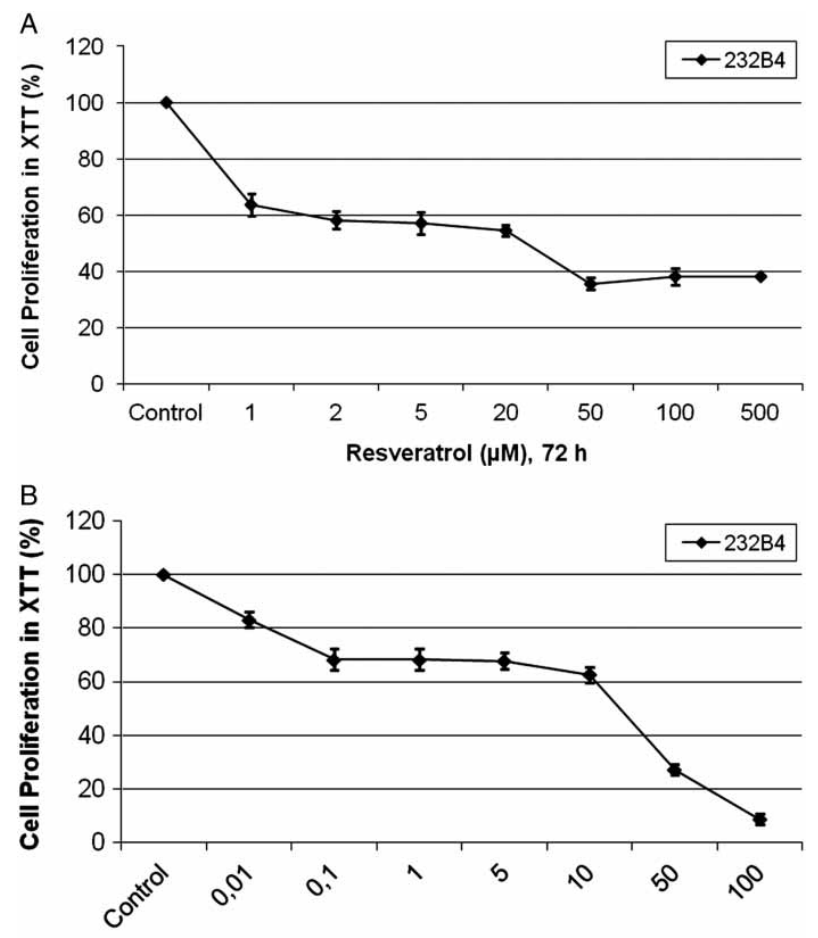

Quercetin $(\mu \mathrm{M}), 72 \mathrm{~h}$

Figure 1 Cytotoxic effects of resveratrol (A) and quercetin (B) on human 232B4 CLL cells. The IC50 values of resveratrol and quercetin were calculated from cell proliferation plots. The results are the means of three independent experiments. The error bars represent the standart deviations. temperature for 10 minutes. Then, cell cycle profiles of the cells were analyzed by flow cytometry.

\section{Results}

Resveratrol and Quercetin decreased proliferation of human 232B4 CLL cells in a dose dependent-manner. In order to determine antiproliferative effects of resveratrol and quercetin on 232B4 CLL cells, MTT cell proliferation assay was conducted after 72 hours incubation period of CLL cells with increasing concentrations of Resveratrol and Quercetin. The results displayed that resveratrol and quercetin caused dose-dependent decreases in 232B4 proliferation as compared to untreated control samples. IC50 valuses of resveratrol (Fig. 1A) and quercetin (Fig. 1B) were found to be 27 - and $24 \mu \mathrm{M}$, respectively.

Resveratrol and Quercetin induce apoptosis in 232B4 cells. Changes in caspase-3 enzyme activity, loss of MMP and Annexin-V-FITC staining to determine apoptotic cell populations were examined in order to demonstrate apoptotic effects of resveratrol and quercetin on 232B4 CLL cells. As shown in Fig. 2A, there were 2-, 16-, 38-, 49- and 107\% increases in caspase- 3 activity in response to $0,5-, 1-, 10-, 50$ and $100 \mu \mathrm{M}$ resveratrol, respectively. $0,1-, 5,10$ and $50 \mu \mathrm{M}$ quercetin increased caspase-3 activity 3-, 12-, 38 and $47 \%$, respectively.
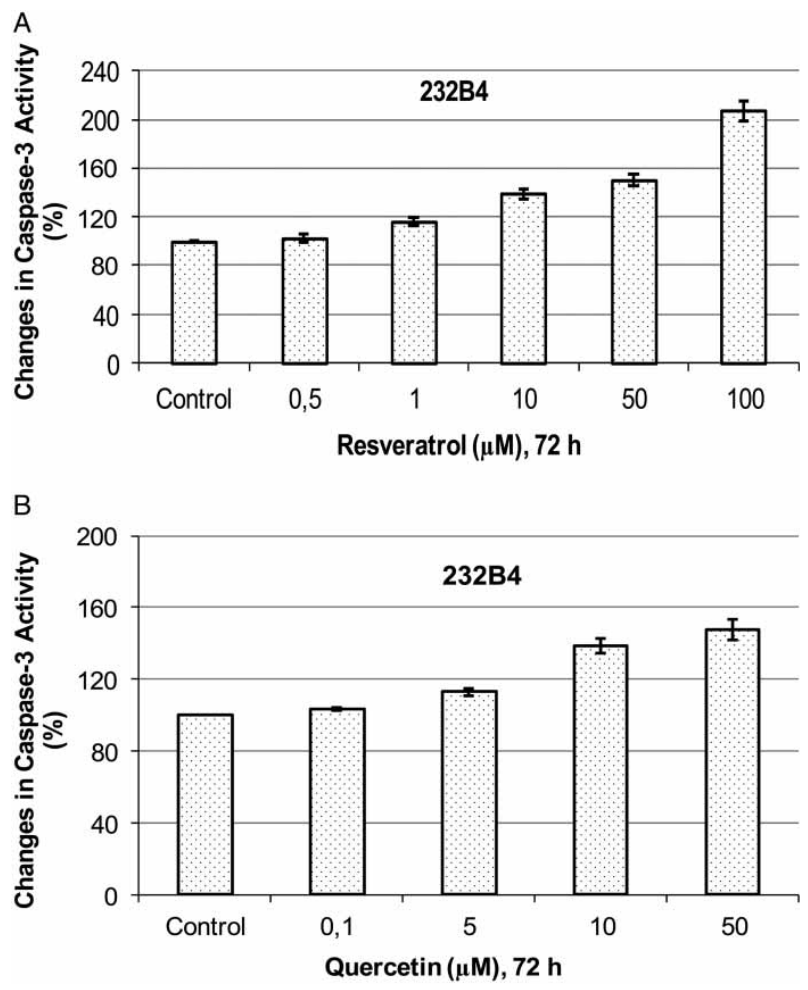

Figure 2 Changes in caspase-3 enzyme activiy in response to resveratrol (A) and quercetin (B). The results are the means of three independent experiments. The error bars represent the standart deviations. 
Resveratrol and quercetin induced apoptosis was further confirmed by Annexin V-FITC/PI double staining. Annexin V-positive/PI negative cells were considered early apoptotic, Annexin V-positive and PI positive cells were late apoptotic. After 48 hours of treatment of 232B4 cells with stepwise increasing concentrations of resveratrol (Figs. 3A and 3B) and quercetin (Figs. 4A and 4B), total apoptotic cell population (late apoptotic plus early apoptotic) increased in a dose-dependent manner. There were 2-, 8-, 133-, 350and $382 \%$ increases in apoptotic cells in response to 0,5-, 1-, 10-, 50- and $100 \mu \mathrm{M}$ resveratrol, respectively, as compared to untreated 232B4 cells (Figs. 3A and 3B). Quercetin increased apoptotic cell population 56-, 133-, 160-, 297- and 331\% in response to 0,1-, 1, 10-, 50- and $100 \mu \mathrm{M}$, respectively (Figs. 4A and 4B).

Resveratrol and Quercetin inhibits cell cycle progression. Cell cycle analysis using flow cytometry was carried out to determine if resveratrol and quercetin inhibits cell proliferation. The results revealed that resveratrol application increased percentage of cell population in $\mathrm{G} 0 / \mathrm{G} 1$ phase, which was accompanied by a corresponding reduction in the percentage of cells in $\mathrm{S}$ phase in a dose dependent manner (Fig. 5). Treatment with quercetin increased the cell population at $\mathrm{G} 0 / \mathrm{G} 1$ and decreased the percentage of cells in $\mathrm{G} 2 / \mathrm{M}$ phases at the same time as compared to untreated control (Fig. 6).

\section{Discussion}

In present study, we demonstrated that resveratrol and quercetin inhibits cell proliferation and cell cycle progression and induces apoptosis in CLL cells. $\mathrm{IC}_{50}$ values of resveratrol and quercetin was 27 - and $24 \mu \mathrm{M}$, respectively. Cytotoxic effects of resveratrol on different types of cells have been reported previously. $\mathrm{The}^{\mathrm{IC}} \mathrm{C}_{50}$ for resveratrol was $45 \mu \mathrm{M}$ on lung cancer cells and this concentration is effective on many tumor cell types. Resveratrol may possess potential therapeutic activity against lung cancer cells, without significantly affecting the viability of normal cells at its therapeutic concentrations. ${ }^{23}$ Resveratrol suppressed the colony-forming growth of OCI/AML and OCIM2 cell lines in a dose-dependent fashion at concentrations ranging from 10 to $75 \mu \mathrm{M}$. In most studies, resveratrol was used at concentrations ranging from 5 to $100 \mu \mathrm{M} .{ }^{19}$ It was reported that quercetin, at a concentration of $20 \mathrm{mM}$, exhibits an antiproliferative effect on U937 cells. ${ }^{19}$ Quercetin inhibited cell proliferation in a dose-dependent manner without affecting cell viability. Quercetin-induced inhibition of cell proliferation has been reported for various cancer cells. ${ }^{24}$

Caspase-3, a key factor in apoptosis execution, is the active form of procaspase- $3^{25}$ whose activation downstream in the apoptotic cascade is essential for leukemia cell apoptosis. ${ }^{26} \mathrm{We}$ used an approach similar to that in a previous study in which we tested the effect of resveratrol on caspase-3 activity in CLL cells. Resveratrol activated caspase-3 in CLL cells. We previously demonstrated activation of caspase- 3 enzyme activity in response to resveratrol in imatinib-sensitive and -resistant chronic myeloid leukemia and acute promyelocytic leukemia cells. ${ }^{27}$ Estrov et al. applied resveratrol and two caspase inhibitors on OCIM2 cells and reported that both caspase inhibitors partially reversed the antiproliferative effect of resveratrol. To further determine whether resveratrol activates the caspase pathway, they incubated OCIM 2 cells in the absence or presence of resveratrol. Incubation of OCIM2 cells with resveratrol reduced the levels of procaspase-3, and increased the levels of the biologically active caspase- $3 .{ }^{28}$ Our results were in agreement with the previous studies.

Resveratrol, through different regulatory mechanisms, has been shown to induce apoptosis in tumor cells. ${ }^{29-32}$ The mechanisms of resveratrol-induced suppression of cellular proliferation have been reported to involve the induction of apoptosis through Fas/CD95, mitochondrial and p53 mediated pathways, ${ }^{29-32}$ upregulation of CHOP gene expression. ${ }^{33}$ In addition, resveratrol suppressed NF-kB and protein kinase-C activity, and modulated the angiogenesis and expression of various growth factors as well as $\mathrm{NO} /$ NOS. ${ }^{34-38}$ Our group previously reported that resveratrol triggers apoptosis through up-regulating longevity assurance (LASS) genes that generate apoptotic ceramides and by down-regulating sphingosine kinase-1 and glucosylceramide synthase genes that convert apoptotic ceramides to antiapoptotic sphingosine-1phosphate and glucosylceramide lipids, respectively, in acute myeloid leukemia and CML cells. ${ }^{12,13}$ Lee et al. observed that quercetin inhibits cell growth and induces apoptosis in colon cancer cells, and that this may be mediated by its ability to down-regulate ErbB2/ErbB3 signaling and Akt pathway. ${ }^{13}$ Quercetin-induced apoptosis in SW-872 human liposarcoma cells was associated with the loss of mitochondrial membrane potential. The apoptosis in SW-872 human liposarcoma cells induced by quercetin was mediated through the activation of caspase-3, Bax, and Bak and then cleavage of PARP and downregulation of Bcl-2. ${ }^{12}$ Kim et al. showed that antiproliferative effect of quercetin is mediated via inhibition of PI-3 kinase in cancer cells. ${ }^{24}$

Our results revealed that resveratrol treatment induced a dose-dependent increase in the percentage of cells in G0/G1 phase, which was accompanied by a corresponding reduction in the percentage of cells in $\mathrm{S}$ phase. A number of studies reported that variety of different human cancer cell lines, treated with resveratrol at micromolar concentrations, arrested the cell cycle progression in $\mathrm{S}$ phase ${ }^{39}$ or less frequently 

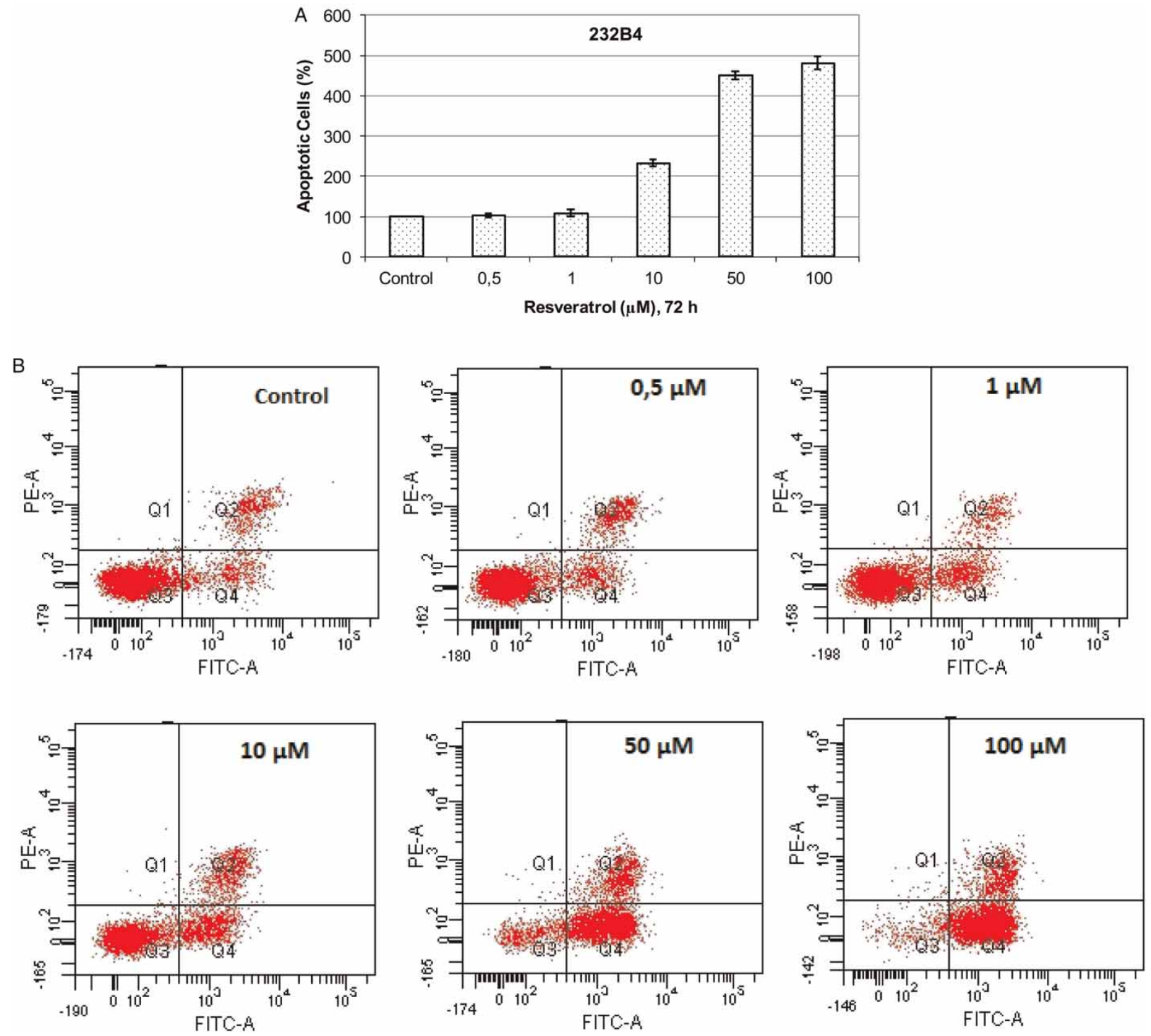

Figure 3 Evaluation of apoptosis in 232B4 cells induced by resveratrol. The percentage of cells undergoing early and late apoptosis in a dose-dependent manner as compared to control and FACS analysis via Annexin V-FITC/PI staining (A \& B). Cells in the lower right quadrant indicate Annexin-positive/PI negative, early apoptotic cells. The cells in the upper right quadrant indicate Annexin-positive/PI positive, late apoptotic.

in the $\mathrm{G} 2 / \mathrm{M}$ phase. ${ }^{40}$ Resveratrol has been shown to modulate the major cell cycle mediators at micromolar concentrations, arresting cancer cells at the G1/S phase of the different cancer cell. ${ }^{25}$ After exposure to $50 \mu \mathrm{M}$ resveratrol, $64.6 \%$ of the AML cells were arrested at the $\mathrm{S}$ phase, whereas only $10.9 \%$ were at the $\mathrm{G} 2 / \mathrm{M}$ phase and $13.6 \%$ at the $\mathrm{G} 0 / \mathrm{G} 1$ phase of the cell cycle. ${ }^{33}$ Parka et al. observed that resveratrol arrested cell cycle progression in the S through G2/ M phase in human histiocytic lymphoma U-937 cells. ${ }^{39}$ Della Ragione et al. reported that lower concentrations of resveratrol is a differentiation-inducer, causing arrest in the S-phase without subsequent apoptosis in HL60 leukemia cells. ${ }^{39}$ Treatment with quercetin increased the cell population at G0/G1 and decreased the percentage of cells in $\mathrm{G} 2 / \mathrm{M}$ phases at the same time as compared to control. On the contary, in previous studies, it was shown that
U-937 cells treated with quercetin remarkably accumulated in the $\mathrm{G} 2 / \mathrm{M}$ phase of the cell cycle in a time dependent manner up to approximately $80 \%$ by 24 hours ${ }^{19}$ and U-937 cells were accumulated mainly at $\mathrm{G} 2 / \mathrm{M}$ phase when incubated with $50 \mathrm{mM}$ quercetin for 24 hours. ${ }^{41}$ Kang and Liang showed that quercetin inhibited the growth of HL-60 leukemia cells in a dosedependent manner and increase the cell number in $\mathrm{G} 2 / \mathrm{M}$ phase. $^{42}$

The results of this study clearly revealed that resveratrol and quercetin induce apoptosis in 232B4 human CLL cells. Furthermore, our results indicated that the growth-inhibitory property of quercetin and resveratrol was mainly due to the induction of apoptosis as evidenced by collapse of mitochondrial membrane potential and activation of caspase-3. These results also suggest that quercetin and resveratrol may be useful for the treatment of human CLL. 

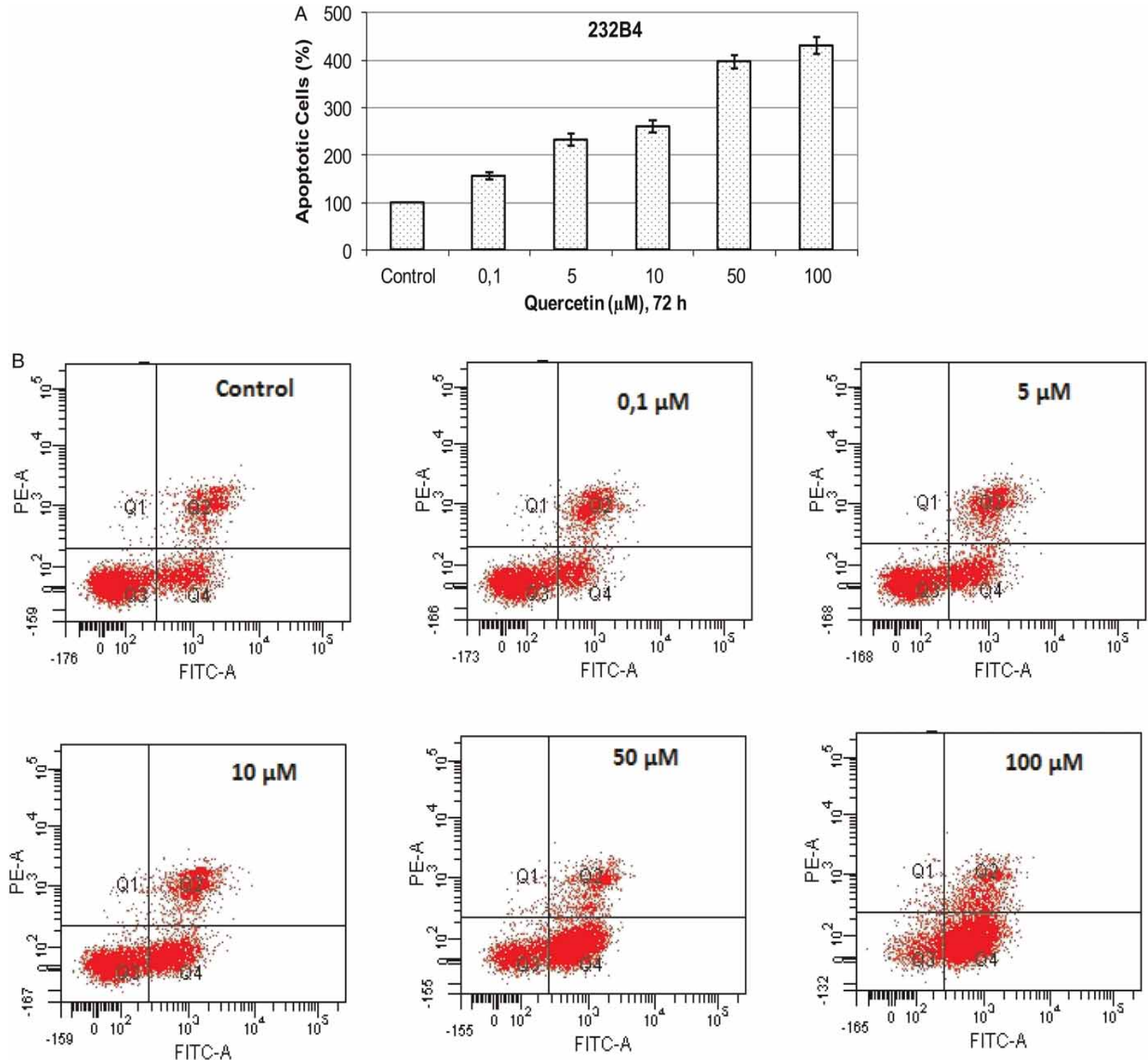

Figure 4 Evaluation of apoptosis in 232B 4 cells induced by quercetin. The percentage of cells undergoing early and late apoptosis in a dose-dependent manner as compared to control and FACS analysis via Annexin V-FITC/PI staining (A \& B). Cells in the lower right quadrant indicate Annexin-positive/PI negative, early apoptotic cells. The cells in the upper right quadrant indicate Annexin-positive/PI positive, late apoptotic.

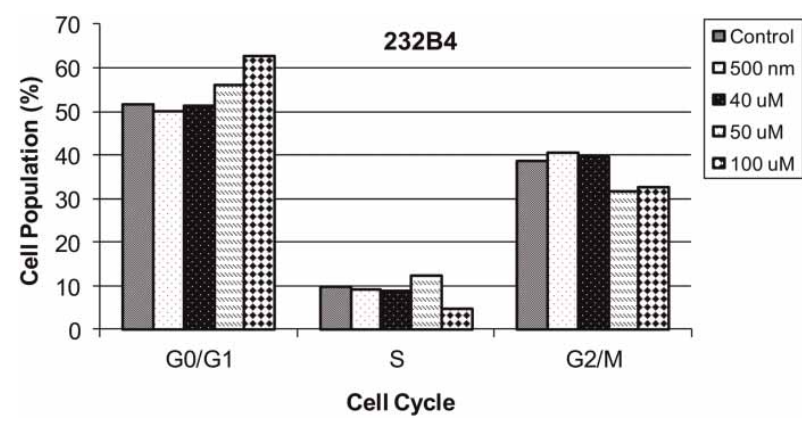

Figure 5 Effect of resveratrol on cell cycle. The percentage of cell cycle phases are shown in the graphs.

\section{Conflicts of interest statement}

We, the authors of the manuscript, do not have any conflicts of interest.

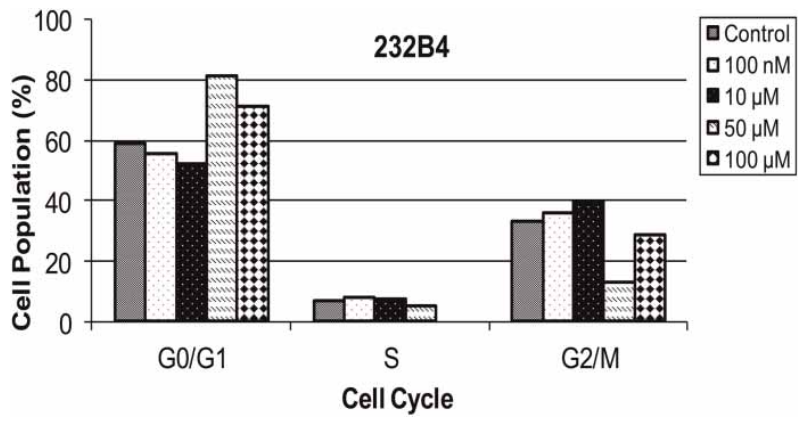

Figure 6 Effect of quercetin on cell cycle. The percentage of cell cycle phases are shown in the graphs.

\section{Acknowledgments}

We thank Biotechnology and Bioengineering Center staff of Izmir Institute of Technology for their help and technical support. This study was supported by 
the Turkish Academy of Sciences Outstanding Young Investigator Programme.

\section{References}

1 Rozman C, Montserrat E. Chronic lymphocytic leukemia. The New England Journal Of Med. 1995;333(16):1052-7.

2 Chiorazzi N, Rai KR, Ferrarini M. Mechanisms of disease. Chronic lymphocytic leukemia. N Engl J Med. 2005;352:804-15.

3 Podhorecka M, Halicka D, Klimek P, Kowal M, Chocholska S, Dmoszynska A. Resveratrol increases rate of apoptosis caused by purine analogues in malignant lymphocytes of chronic lymphocytic leukemia. Ann Hematol. 2011;90:173-83.

4 Zenz T, Mertens D, Döhner H, Stilgenbauer S. Importance of genetics in chronic lymphocytic leukemia. Blood Rev. 2011;25: 131-7.

5 Byrd JC, Stilgenbauer S, Flinn IW. Chronic lymphocytic leukemia. Hematology AM Soc Hematol Educ Program. 2004;163-83.

6 Hamblin T. Natural products and the treatment of leukemia. Leukemia Res. 2006;30:649-50.

7 Shimizu T, Nakazato T, Ji XM, Sagawa M, Ikeda Y, Kizaki M. Resveratrol induces apoptosis of human malignant $\mathrm{B}$ cells by activation of caspase-3 and p38 MAP kinase pathways. Biochemical Pharmacol. 2006;71:742-50.

8 Dong Z. Molecular mechanism of the chemopreventive effect of resveratrol. Mutation Res. 2003;523(524):145-50.

9 Liao HF, Kuo CD, Yang YC, Lin CP, Tai HC, Chen YY, et al. Resveratrol enhances radiosensitivity of human non-small cell lung cancer NCI-H838 cells accompanied by inhibition of nuclear factor-kappa B activation. J Radiat Res. 2005;46(4):387-93.

10 Ferry-Dumazet H, Garnier O, Mamani-Matsuda M, Vercauteren J, Belloc F, Billiard C, et al. Resveratrol inhibits the growth and induces the apoptosis of both normal and leukemic hematopoietic cells. Carcinogenesis. 2002;23(8):1327-33.

11 Bae S, Lee EM, Cha HJ, Kim K, Yoon Y, Lee H, et al. Resveratrol alters microRNA expression profiles in A549 human non-small cell lung cancer cells. Mol Cells. 2011;32(3):243-9.

12 Kartal M, Saydam G, Sahin F, Baran Y. Resveratrol triggers apoptosis through regulating ceramide metabolizing genes in human K562 chronic myeloid leukemia cells. Nutr Cancer. 2011;63(4):637-44

13 Cakir Z, Saydam G, Sahin F, Baran Y. The roles of bioactive sphingolipids in resveratrol-induced apoptosis in HL60 acute myeloid leukemia cells. J Cancer Res Clin Oncol. 2011;137:279-86.

14 Gaur U, Nair AS, Shishodia S, Aggarwa BB, Bhardwaj A, Sethi $\mathrm{G}$, et al. Resveratrol inhibits proliferation, induces apoptosis and overcomes chemoresistance through down-regulation of STAT3 and nuclear factor- $\kappa$ B - regulated antiapoptotic and cell survival gene products in human multiple myeloma cells. Blood. 2007; 109:2293-302.

15 Azhar R, Hussain SU, Rong B, Omar SK, Saeeda OA, Maqbool A, et al. Resveratrol suppresses constitutive activation of AKT via generation of ROS and induces apoptosis in diffuse large B cell lymphoma cell lines. PlosONE. 2011;6(9):1-12.

16 Zhang H, Zhang M, Yu L, Zhao Y, He N, Yang X. Antitumor activities of quercetin and quercetin-5',8-disulfonate in human colon and breast cancer cell lines. Food and Chemical Toxicol. 2012;50:1589-99.

17 Gibellini L, Pinti M, Nasi M, Biasi SD, Roat E, Bertoncelli L, et al. Interfering with ROS metabolism in cancer cells: the potential role of quercetin. Cancers. 2010;2:1288-311.

18 Chien SY, Wu YC, Chung JG, Yang JS, Lu HF, Tsou MF, et al. Quercetin-induced apoptosis acts through mitochondrial- and caspase-3-dependent pathways in human breast cancer MDAMB-231 cells. Hum. Exp. Toxicol. 2009;28:493-503.

19 Lee TJ, Kim OH, Kim YH, Lim JH, Kim S, Park JW, et al. Quercetin arrests G2/M phase and induces caspase-dependent cell death in U937 cells. Cancer Lett. 2006;240:234 42.

20 Gulatı N, Laudet B, Zohrabian VM, Muralı R, Jhanwar-Uniyal M. The antiproliferative effect of quercetin in cancer cells is mediated via inhibition of the PI3 K-Akt/PKB pathway. Anticancer Res. 2006;26:1177-82.

21 Banerji V, Johnston JB, Seftel MD. The role of hematopoietic stem cell transplantation in Chronic Lymphocytic Leukemia. Transfusion and Apheresis Sci. 2007;37:57-62.

22 Piskin O, Ozcan MA, Ozsan GH, et al. Synergistic effect of imatinib mesylate and fludarabine combination on Philadelphia chromosome-positive chronic myeloid leukemia cell lines. Turk J Hematol. 2007;24:23-7.

23 Aziz MH, Kumar R, Ahmad N. Cancer chemoprevention by resveratrol: in vitro and in vivo studies and the underlying mechanisms, Int J Oncol. 2003;23(1):17-28.

24 Kim YJ, Bae YC, Suh KT, Jung JS. Quercetin, a flavonoid, inhibits proliferation and increases osteogenic differentiation in human adipose stromal cells, Biochem Pharmacol. 2006;72: 1268-78.

25 Fan TJ, Han LH, Cong RS, Liang J. Caspase family proteases and apoptosis. Acta Biochimica et Biophysica Sinica 2005; 37(11):719-27.

26 Datta R, Banach D, Kojima H, Talanian RV, Alnemri ES, Wong WW. Activation of the CPP32 protease in apoptosis induced by $1-\beta-D$ arabinofuranosylcytosine and other DNA-damaging agents. Blood 1996;88:1936-43.

27 Can G, Cakir Z, Kartal M, Gunduz U, Baran Y. Apoptotic effects of resveratrol, a grape polyphenol, on imatinib sensitive and resistant K562 cronic myeloid leukemia cells. Anticancer Res. 2012;32(7):2673-8.

28 Estrov Z, Shishodia S, Faderl S, Harris D, Van Q, Kantarjian $\mathrm{HM}$, et al. Resveratrol blocks interleukin-1 $\beta$-induced activation of the nuclear transcription factor $\mathrm{NF}-\kappa \mathrm{B}$, inhibits proliferation, causes S-phase arrest, and induces apoptosis of acute myeloid leukemia cells. Blood 2003;102(3):987-95.

29 Dörre J, Gerauer H, Wachter Y, Zunino SJ. Resveratrol induces extensive apoptosis by depoarizing mitchondrial membranes and activating caspase-9 in acute lymphoblastic leukemia cells. Cancer Res. 2001;61:4731-9.

30 Clement MV, Hipira JL, Chawdhury SH, Pervaiz S. Chemopreventive agent resveratrol, a natural product derived from grapes, triggers CD95 signaling dependent apoptosis in human tumor cells. Blood. 1998;92:996-1002.

31 Shih A, Davis FB, Lin HY, Davis PJ. Resveratrol induces apoptosis in thyroid cancer cell lines via a MAPK-and p53-dependent mechanism. J Clin Endcrinol Metab. 2002;87:1223-32.

32 Wooa KJ, Lee TJ, Lee SH, Lee JM, Seo JH, Jeong YJ, et al. Elevated gadd $153 /$ chop expression during resveratrol-induced apoptosis in human colon cancer cells. Biochemical Pharmacol. 2007;73:68-76.

33 Garcia-Garcia J, Micol V, de Godos A, Gomez-Fernandez JC. The cancer chemopreventive agent resveratrol is incorporated into model membranes and inhibits protein kinase $\mathrm{C}$ a-activity. Arch Biochem Biophys. 1999;372:382-8.

34 Kaneuchi M, Sasaki M, Tanaka Y, Yamamoto R, Sakuragi N, Dahiya R. Resveratrol suppresses growth of Ishikawa cells trough down-regulation of EGF. Int J Oncol. 2003;23:1167-72.

35 Hsieh TC, Juan G, Darzynkiewicz Z, Wu JM. Resveratrol increases nitric oxide synthase, induces accumulation of p53 and p21 (WAF/CIP1), and suppresses cultured bovine pulmonary artery endothelial cell proliferation by perturbing progression trough S and G2. Cancer Res. 1999;59:2596-601.

36 Holian O, Wahid S, Atten MJ, Attar BM. Inhibition of gastric cancer cell proliferation by resveratrol: role of nitric oxide. Am J Physiol Gastrointest Liver Physiol. 2002;282:809-1.

37 Athar M, Back JH, Tang X, Kim KH, Kopelovich L, Bickers $\mathrm{DR}$, et al. Resveratrol: a review of preclinical studies for human cancer prevention. Toxicol. Appl. Pharmacol. 2007; 224:274-283.

38 Kima WK, Banga MH, Kima ES, Kang NE, Jung KC, Chod HJ, Park JHY. Quercetin decreases the expression of ErbB2 and ErbB3 proteins in HT-29 human colon cancer cells. Journal of Nutritional Biochem. 2005;16:155-62.

39 Parka JW, Choia YJ, Janga MA, Lee YS, Juna DY, Suh SI, et al. Chemopreventive agent resveratrol, a natural product derived from grapes, reversibly inhibits progression through $\mathrm{S}$ and $\mathrm{G} 2$ phases of the cell cycle in U937 cells. Cancer Lett. 2001;163: 43-9.

40 Della-Ragione F, Cucciolla V, Borrilello A, Della-Pietra V, Racioppi L, Soldati G, Manna C, Galletti P, Zappia V. Resveratrol arrests the cell division cycle at $\mathrm{S} / \mathrm{G} 2$ phasetransition. Biochem Biophys Res Commun. 1998;250:53-58.

41 Lee TJ, Kim OH, Kim YH, Lim JH, Kim S, Park JW, Kwon TK. Quercetin arrests G2/M phase and induces caspase-dependent cell death in U937 cells. Cancer Lett. 2006;240:234 42.

42 Kang TB, Liang NC. Studies on the inhibitory effects of quercetin on the growth of HL-60 leukemia cells. Biochem Pharmacol. 1997;54:1013-18. 